RAKEL GOMEZVAZQUEZ
Universidad del País Vasco UPV/EHU

rakel.gomez@ehu.eus

\title{
Monumentos y plagas biológicas. Una lectura del devenir colonial desde la investigación artística.
}




\section{ABSTRACT}

This investigation tries to interpret the imprint of the anthropocene and its consequences, through the observation of two symbolically colonial elements and their decriminalization. The displacement and replacement of the statue of Columbus in Buenos Aires by the monument of Juana de Azurduy, and the attack of an insect - the Red Palm Weevil - on the palm trees of the northern peninsula, planted as a symbol of colonial success since the late $\mathrm{S}$ XIX. Both contexts -monumental and biologicalare analyzed from artistic practice as cultural constructions, which portray ecological and political-social problems of memory and identity.

\section{Keywords}

monument, iconoclasm, colonialism, invasive species, anthropocene.

\section{RESUMEN}

Esta investigación pretende interpretar la impronta del antropoceno y sus consecuencias, a través de la observación de dos elementos simbólicamente coloniales y su desmonumentalización. El desplazamiento y sustitución de la estatua de Colón en Buenos Aires por el monumento de Juana de Azurduy, y el ataque de un insecto -el Picudo Rojo- sobre las palmeras de la franja norte peninsular, plantadas como símbolo de éxito colonial desde finales del s XIX. Ambos contextos -monumental y biológicoson analizados desde la práctica artística como construcciones culturales, que retratan problemas ecológicos y político-sociales de memoria e identidad.

\section{Palabras clave}

monumento, iconoclastia, colonialismo, especie invasora, antropoceno. 


\section{INTRODUCCIÓN}

Este artículo es el formato texto de la construcción de un relato, una investigación desde la creación que media entre saberes científicos, botánicos e historiográficos. La construcción de un archivo visual que habilita una relectura del paisaje, tomando dos símbolos coloniales. Un modo que he encontrado de cartografiar lo que no es sólo un momento histórico ni un sólo espacio geográfico, rompiendo con la linealidad que se impone en la exposición de los descubrimientos científicos, para hablar de: memoria, colonialismo, explotación y ecología.

\subsection{El poder simbólico del monumento}

La búsqueda incansable de la mímesis que permitió el desarrollo de tecnologías como el medio fotográfico es una de las evidencias del culto a las imágenes en la cultura denominada occidental. Nuestra relación con ellas ha estado marcada tanto por la producción como por su destrucción (Latour, 2002). Como animales simbólicos que somos, interpretamos lo que percibimos dándole un sentido, y de la misma forma, conceptos imperceptibles son convertidos en imágenes (por el mismo proceso de simbolización), para hacerlos perceptibles. Esta proyección y dote de significado simbólico se ha desarrollado a lo largo de la historia con una doble intención, bien buscando una mímesis para comunicar con claridad, o bien generando un mensaje encriptado destinado solo a observadores iniciados. Es precisamente el poder que encierra su capacidad de transmitir mensajes y su uso para difundir ideas y valores lo que ha marcado una manera de habitar el mundo dejando una impronta en nuestro entorno desde la prehistoria (Freedberg, 2017). A veces, de hecho, ha sido este rastro y huella de la producción y destrucción de imágenes, marca de nuestra dialéctica, la que nos ha permitido interpretar hechos históricos y cambios de paradigma. Razón por la cual en el contexto occidental nuestro territorio siempre estuvo circunscrito por imágenes que son condensaciones de relatos. Hablaremos en concreto para esta reflexión sobre como cuaja la memoria en lo que se conoce como monumento. Esculturas u objetos representativos y simbólicos que se ubican en lugares que tienen una carga significativa con el propósito de enfatizar el símbolo. De esta manera símbolo, imagen y emplazamiento enlazan para que aquello que se conmemora no pierda vigencia en el imaginario de quien habita el espacio.

Por monumento, en el sentido más antiguo y primitivo, se entiende una obra realizada por la mano humana y creada con el fin específico de mantener hazañas o destinos individuales o un conjunto de éstos siempre vivos y presentes en la conciencia de las generaciones venideras. (Riegl, 1987, p.23)

El monumento por lo tanto es un artefacto que apelando a mitos y hechos históricos que encierran significados a los que alude, opera en el inconsciente del observador. Esta singularidad ha supuesto que, atendiendo al contexto social y político del momento, el monumento haya recibido el impacto del observador y sociedad a la que interpela. Razón por la cual muchos se han preservado y otros no, dándonos pistas de cómo han discurrido los acontecimientos, de cómo han sido afectados o han afectado a las personas que los rodeaban. El cambio de paradigma y la evolución del pensamiento ha provocado que algunas representaciones hayan sido percibidas con odio, repudiadas o incluso hayan dejado de ser visibles, quedando abandonas. Por lo tanto, en su conservación o destrucción ha influido con determinación la relación que se ha dado con el contexto. La analogía de Grafted Monument (injerto) permite interpretar 
esta relación entre monumentos y sociedad con la que comparte contexto explicando cómo se ve afectada la conservación de la estatuaria pública según la reciprocidad que se establezca entre los habitantes del entorno y la imagen simbólica (Spiekel, 2001). Por esta misma razón la ideología y carácter formal de la imagen quedan a expensas de cómo estos habitantes las acepten e interpreten y cómo evolucione su aceptación e interpretación en el tiempo. Si bien la producción de estatuaria monumental que nos ha acompañado a lo largo de la historia entró en decadencia durante la modernidad al arrancarle su función representativa, el arte contemporáneo, en muchas ocasiones con la intención de revisar y tergiversar la autoridad de estos monumentos, encontró una nueva forma de iconoclastia que produce arte.

La estatua de Colón, símbolo de un relato colonial junto a las palmeras indianas, plantadas para celebrar "que ahí vivía uno que había logrado hacer las Américas", simbolizan el descubrimiento y/o conquista de América. Al convertirse hoy en un relato que está siendo revisado con el objetivo, entre otros, de hacer justicia y reconocer símbolos y alteridades que fueron negadas, la figura de Colón se ha convertido en una figura incómoda que ha propiciado, dentro y fuera del contexto del arte contemporáneo, actos de iconoclastia y remoción de los monumentos que conmemoraban su figura. Prueba de la controversia que genera son algunos de los hechos que han acontecido en diferentes lugares y esculturas del mundo en los últimos años: fue juzgado y derribado en Caracas en el año 2004, intervenido en Barcelona, vandalizado en Valladolid y retirado de Los Ángeles y Nueva York.

Frente a la solemnidad inerte de una escultura, como las que representan a Colón, traigo a la observación en paralelo un ser vivo, una planta marcada por su carácter orgánico y natural. Elegiré como caso paradigmático las palmeras indianas ${ }^{1}$ de La Quinta Guadalupe, actual archivo de indianos en la Villa de Colombres, municipio de Ribadedeva, Asturias. Lugar en el que además de numerosas casas indianas se emplaza esta Fundación Archivo de Indianos ${ }^{2}$ del cual una parte es el Museo de la Emigración de Asturias, ocupando precisamente esta casa indiana La Quinta Guadalupe. En concreto me referiré como caso de estudio a las palmeras ubicadas en esta casa construida por el emigrante asturiano Íñigo Noriega de Lasso en 1960, por su valor simbólico e institucional actual, y por lo que añade la figura del propietario a la investigación que nos ocupa dada su responsabilidad en el ecocidio del lago Chalco.

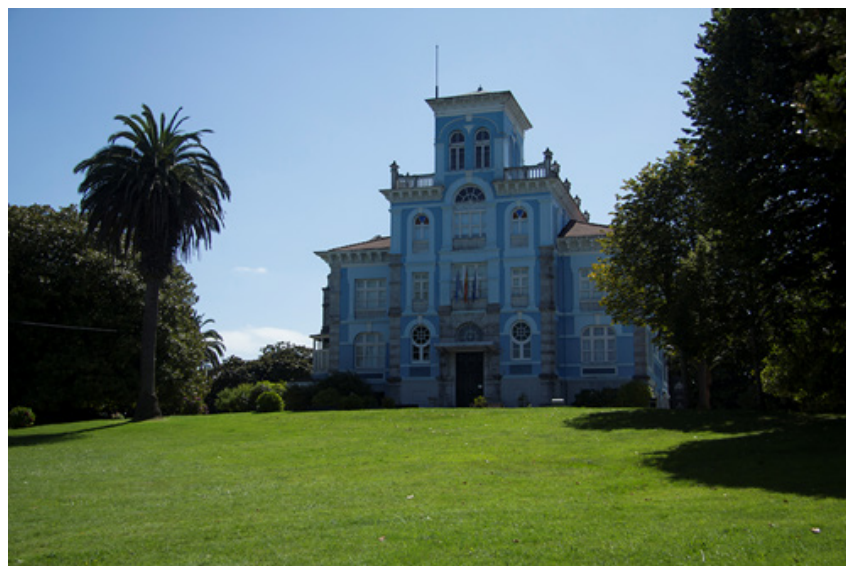

Figura 1. La Quinta Guadalupe, casa construida por el emigrante asturiano Íñigo Noriega de Lasso. Fuente: https://www.rakelgomezvazquez.com 
En Colombres destaca la famosa Quinta Guadalupe, fastuosa construcción realizada por el mítico Íñigo Noriega y sede actual del Archivo de Indianos; en su página oficial se glosa la biografía de este indiano y entre sus múltiples logros está la desecación del lago de Chalco del que haría una explotación agrícola, en la que trabajaban de 2.000 a 3.000 obreros. El lago se encuentra en Xico, un municipio de las afueras de la capital mexicana, y es uno de los lagos sobre los que se asentaba el imperio azteca (Somovilla, 2015, p.12).

Cabe comentar que observo estos dos elementos para desarrollar esta reflexión y en ambos contemplo monumentos por su condición de símbolo colonial y por su emplazamiento. Si bien la naturaleza material para representar símbolos se desarrolla en parámetros antagonistas, lo fósil e inerte frente a la vida, entiendo que ambos son condensaciones de memoria con una intención monumental. Recupero a Le Goff (1989) que reseña esa intención marcada de aviso para recordar de los monumentos:

La palabra latina monumentum está ligada a la raíz indoeuropea men que expresa una de las funciones fundamentales de la mente (mens), la memoria (memini). El verbo monere significa hacer recordar, de donde avisar, iluminar, instruir. El monumentum es un signo del pasado. El monumento si nos atenemos a los orígenes filológicos, es todo aquello que puede reclamar el pasado, perpetuar el recuerdo, por ejemplo, los actos escritos. (p.104)

El paradigma simbólico e incluso cierta verticalidad es compartida en ambos, aunque biológicamente sean no solo diferentes sino quizá incluso contrarios. Ambos concentran la idea de poder y hoy padecen por su dimensión simbólica. Cuando estos monumentos a Colón fueron construidos y ubicados, se hizo con la misma intención política y simbólica que Îñigo Noriega de Lasso hizo plantar aquellas palmeras indianas en sus terrenos: la intención de inmortalizar un mensaje y un relato conmemorativo. En este tiempo y contexto ambos objetos simbólicamente legitiman un discurso colonial y padecen las consecuencias de representar lo que representan. Esta es una de las hipótesis con las que avanza esta investigación que a continuación presento. Si el monumento se vincula a un pasado y a la memoria, la palmera también es parte de nuestro patrimonio que fue plantado con una manifiesta intencionalidad de comunicar un mensaje y por lo tanto su mensaje se revisa y reedita dadas sus vicisitudes en la contemporaneidad. Su condición de monumento vivo añade la complejidad de interpretar que las circunstancias que sufre tienen raíz en lo mismo que simbólicamente representa.

\section{Colón desahuciado}

Me encontraba en Buenos Aires, Argentina, en las fechas en las que se inauguraba la nueva escultura de Juana Azurduy la cual era ubicada en el lugar que antes había ocupado el monumento a Colón. El emplazamiento, la plaza trasera de la Casa Rosada (Casa de Gobierno en la República Argentina) es el punto extremo de un eje que vertebra el poder político en el espacio urbano de la capital. De hecho, si trazamos una línea que tome como punto de partida este emplazamiento, se dibuja un eje simbólico que atraviesa el espacio urbano conectando Casa Rosada, Plaza de Mayo y Congreso de la Nación. 


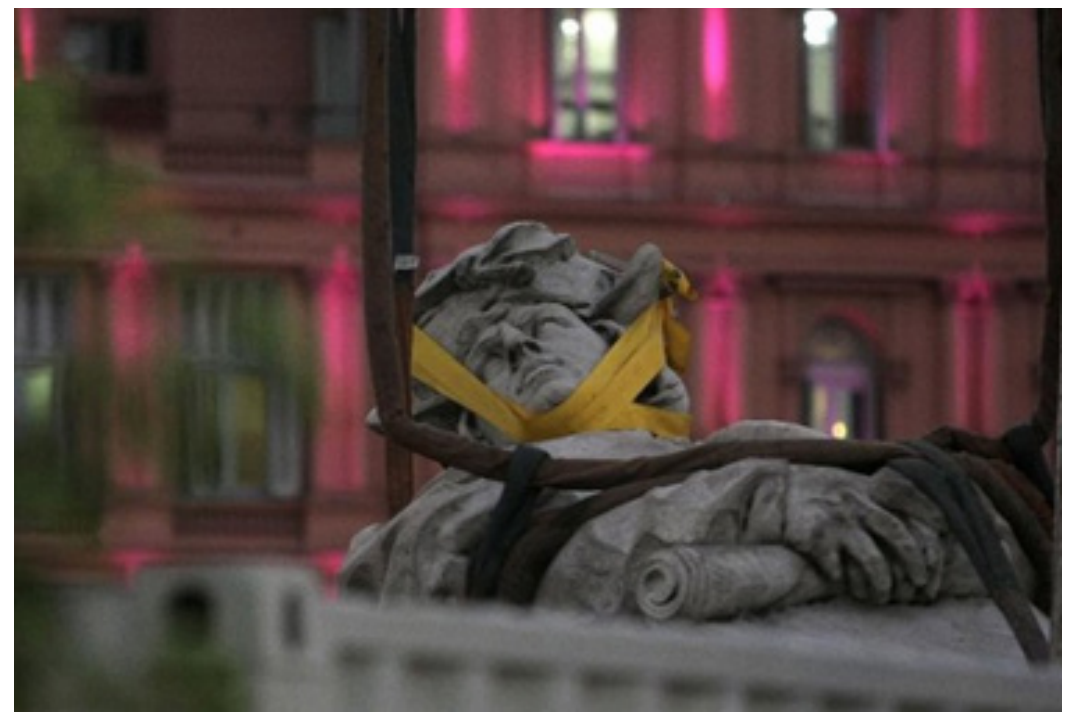

Figura 2. La polémica sobre su traslado ha durado años. Comenzó en junio de 2013, el año que la escultura empezó a ser desmantelada.

Fuente: https://diariocorreo.pe/mundo/argentina-retira-polemica-estatua-de-colon-e-91009/

La imagen del aventurero genovés fue donada por la colectividad italiana en 1910 para conmemorar los primeros 100 años de Argentina como nación. Tallado por Arnaldo Zocchi, realizado en Italia con mármol de Carrara, el Monumento fue inaugurado el 15 de junio de 1921 y permaneció desde entonces junto a la presidencia hasta su traslado a la Costanera Norte. Quedando destronado, cien años después, de la cabecera icónica del poder político para la conmemoración del segundo centenario, cuando en su lugar queda instalado el monumento en honor a Juana Azurduy. Es necesario contextualizar el personaje de Juana, guerrera contra las tropas realistas españolas durante la independencia del virreinato del Río de la Plata, en el siglo XIX. Desde 2009 generala, momento en el que fue ordenado su ascenso por Cristina Kirchner. Azarduy es la imagen de las heroínas que lucharon por la independencia de Iberoamérica del imperialismo español. Luchó contra el control español desde el lado de los ejércitos populares (Calero, 2015).

Juana: mujer, heroína, mestiza y rebelde. La estatua que hoy le rinde homenaje fue una donación de Evo Morales, presidente entonces de Bolivia y se construyó en las instalaciones de la ex-ESMA (antiguo campo de concentración en el que desaparecieron 5000 personas durante la dictadura militar argentina, un lugar de alto contenido simbólico para la memoria, verdad y justicia). Las lecturas políticas abarcan el traslado, la conservación, la sustitución, la localización final de Colón y también los donantes. Es decir, hacen de la intervención una obra que es política de estado para una memoria descolonizada (Padin, 2015).

Era marzo de 2013 cuando el monumento a Colón comenzó a ser desmantelado, decisión que generó y genera controversia. Las autoridades de la Ciudad Autónoma de Buenos Aires protestaron y estaban en contra de la decisión tomada por el gobierno de la nación y la Justicia dispuso detener la desmantelación. Incluso el 3 de junio, Día del Inmigrante Italiano en la Argentina, el Comité de los Italianos en el Exterior y la Federación de Asociaciones Italianas en 
Buenos Aires junto a las ONG: Salvemos a las Estatuas y Basta de Demoler ${ }^{3}$, se congregaron tras la casa Rosada para exigir, sin éxito, que se detuviera el proyecto.

\subsection{Juana de Azurduy. Cambio de paradigma}

Las relaciones entre monumentos y poder para conmemorar las celebraciones del primer y segundo centenario de la fundación de la nación argentina, ilustran un cambio de paradigma ${ }^{4}$. Una traducción de la historia americana que hasta ahora estaba instalada en el imaginario y en el espacio público. El desplazamiento de la estatua de Colón para acoger la de Juana, una estatua que es sustituida por otra es una expresión de ello. El cambio de perspectiva tiene un reflejo directo en el arte monumental, en las imágenes que se construyen y en los lugares que estos ocupan. Las transformaciones estéticas como resultado de transformaciones políticas. Tomar el espacio público es inscribirse en el mundo, es por ello que el poder históricamente ha tomado los emplazamientos simbólicos y ha inscrito sus ideales y pensamientos en él (Gamboni, 2014).

De hecho, la posición de la nueva escultura está en correspondencia con una nueva dirección de la mirada. Mientras que Juana mira hacia la casa Rosada, hacia América, Colón anteriormente miraba hacia Europa, con la carga simbólico-política que esto tiene. El relato del grupo que acompaña a ambas figuras también enlaza con discursos antagónicos. Mientras que a Colón le acompañan grupos escultóricos que representan entre otros la Ciencia, la Civilización, y la Fe, la construcción e instalación del grupo escultórico de 25 toneladas de bronce que representa a Juana en lucha, se completa con sus cuatro hijos, uno de ellos un bebé que lleva a la espalda. Está acompañada además por un indio Tarabuqueño, un Koya, un Aimara, un Quechua, una anciana, una joven, y un gaucho de Güemes en su caballo. Ilustrando así la diversidad de los pueblos originarios de Argentina.

En la intención que pretende un cambio de paradigma también hay una cuestión de género. Con la inclusión de referentes femeninos en una nueva galería de celebridades argentinas se visibiliza la participación de las mujeres en los acontecimientos históricos de los que por costumbre han sido obviadas. Nuestra heroína además es mestiza y rebelde. Hija de un rico español, Matías Azurduy, de raza blanca, que se había casado con Eulalia Bermúdez, una indígena proveniente de Chuquisaca, Bolivia. Juana se educó y creció en el Convento de Santa Teresa de esa localidad. Su rebeldía no permitió que se adaptara a la vida conventual y pocos años después fue finalmente expulsada. (Pigna, 2020)

Esta figura de Juana Azurduy además no viene de Europa ni la dona un europeo/a. Aunque, consecuencias de la propia colonialidad, su autor Andrés Zerneri siendo un artista argentino es de origen italiano. El mismo Zerneri reconoce que tiene pasaporte italiano, y no se siente agraviado por el traslado de Colón, ya que no reconoce en él el símbolo del que le hablaron cuando era un niño, sino la imagen de una cultura impuesta sobre otra ${ }^{5}$.

El espacio ocupado por la figura de Colón al ser reemplazado por la figura de Juana de Azurduy transforma las ideas de colonización, dependencia, sumisión, conquista, disolución de lo propio, inscriptas en la primera, por las de independencia, soberanía, libertad, reconocimiento, autonomía, diversidad, inscriptas en la segunda) esta circunstancia muestra a las claras que la Memoria se convierte en un camino que descubre lo oculto del pasado, denuncia las tragedias, las luchas acalladas y, en manos del pueblo y de los conductores que pertenecen a él, anuncia y construye un presente 
enriquecedor que ilumina un futuro de justicia y verdad (Padin, 2015, p.12).

El motivo del traslado y sustitución pretende una puesta en práctica liberadora y decolonial desde la creación de una nueva cartografía urbanística y simbólica para la ciudad. Colón tomó posesión de la naturaleza y de los naturales fundamentando y consolidando el eurocentrismo y el etnocentrismo, la colonialidad. Su permanencia en este lugar representaba una cultura impuesta y hasta ahora naturalizada. Juana lleva una espada en la mano izquierda. El artista asegura que, aunque probablemente era diestra, quiere pensar que al representarla sujetándola en su mano izquierda y por la posición del brazo, es como una bandera que porta. Una espada que no mata, sino que libera ${ }^{6}$. Esta hipernarratividad tiene como resultado la construcción de un símbolo cerrado y sin fisuras, no dando lugar a la construcción subjetiva lo cual estaría desplazando al monumento del arte. Esta política pedagógica de mensaje cerrado en la figura de Juana desplazando a Colón demanda nuevos debates y la señala como la punta del iceberg, una excusa para una revisión oficial necesaria de los objetivos y medios de una memoria descolonizada.

\subsection{Palmeras indianas}

En el 2013, mientras el monumento de Colón en Buenos Aires empieza a ser desmantelado para su traslado, al otro lado del océano en Gondomar, Vigo, se registra el que será el primer caso de picudo rojo en una palmera indiana.

Estas palmeras ${ }^{7}$, símbolo colonial ${ }^{8}$ por excelencia, celebraban que "allí vivía uno que lo había logrado", había logrado "hacer las américas". Actualmente en muchos de los casos son los últimos testigos vivos de aquel fenómeno migratorio de finales del s. XIX y principios del XX que marcharon buscando un futuro mejor en un tiempo de escasez en la península. De aquella emigración, uno de los grandes éxodos del s. XIX, pocos lograron retornar y solo algunos, los que menos, como recoge la RAE, lo hacían siendo ricos (Morales Saro y Llordén Miñambres, 1992). A ellos, y solo a ellos, se les conoce como indianos. Estos indianos, emigrantes retornados ricos, además de promover obras como la construcción de escuelas o instalaciones de agua y saneamientos en sus pueblos de origen, construían casas para sí mismos en las que instalarse durante los veranos o para retirarse en su hipotético regreso definitivo. A lo largo de la franja norte peninsular, palmeras centenarias marcan como faros esbeltos estas antiguas moradas de los que lograron volver con éxito económico y social. Eclécticas, sin una tipología concreta ${ }^{10}$, aunque todas con cierto aire colonial, están habitualmente rodeadas de grandes jardines en los que se plantaban, como en aquel entonces demandaba la época, árboles y plantas exóticas. Tuyas, magnolios y araucarias es la triada que habitualmente se repite junto a las palmeras llamadas indianas, especialmente la variedad canariensis (Santos González, 2020).

Plantadas en la mayoría de los casos junto a las entradas (en mayor o menor número según su poder adquisitivo) eran ejemplares que traían en sus viajes de ultramar y compradas al parar en Canarias, último puerto antes de atracar en el continente. Las plantaban, como símbolo de riqueza, lujo y poder. Las mismas razones por las que más tarde en los 90, en pleno boom inmobiliario, las plantarían en las avenidas y urbanizaciones de zonas de costa del Levante, en tal número que agotaron las existencias de los viveros nacionales y obligaron a importar ejemplares que estaban infectados con picudo rojo. Grabado en nuestro imaginario, desde que Colón las describiera en su primer viaje a América, la palmera es emblema de conquistadores y exotismo ${ }^{11}$. Nuestra cultura occidental, sin embargo, relacionada desde su origen con las 
culturas del mediterráneo, reconoce desde antes la palmera como señal de oasis en medio del desierto, es decir, la silueta de una palmera avisando de la cercanía del agua y por lo tanto de la vida, una de las ilustraciones del paraíso. Su verticalidad, como la de obeliscos o cipreses, las convierte en depositarios de significados míticos que enlazan cielo y tierra. En nuestro inconsciente colectivo las reconocemos como imagen inequívoca de lugar exótico y opulento, símbolo con el que estos indianos señalarán su patrimonio a la vuelta al hogar que los vio nacer. La consolidación del emprendimiento emigrante, un símbolo de poder y de la construcción de un sueño como conquistadores de paraísos terrenales.

Las palmeras como parte de los jardines de los indianos pertenecen al mundo vegetal criaturas serviles cuyo fin se cifra en satisfacer nuestros intereses y necesidades (Mancuso y Vittola, 2015). Nuestra relación con las plantas es reveladora de nuestra tendencia imperialista sobre los seres que consideramos inferiores. Tal es así que mientras hay numerosos registros de la arquitectura indiana (a pesar de ser un orden que no se puede clasificar), no hay registros de la plantación en ninguna de las casas que he visitado, ni tampoco en el Archivo de Indianos. De hecho, muchas han desaparecido con las ampliaciones de carreteras y $\operatorname{caminos}^{12}$. Al estar ubicadas en las calles principales sucumbieron con la llegada del tráfico rodado. Así mismo, he recogido en testimonios orales que muchas, debido a la envergadura y el alcance de sus raíces, los dueños en muchos casos las vieron como factores de riesgo para sus casas y fueron taladas. La pérdida del capital que llegaba desde ultramar y sostenía aquellas casas y patrimonios, ha supuesto en muchos casos su abandono y posterior desaparición. En algunos casos, sin embargo, es precisamente este abandono y su altura lo que las deja como mástiles que señalan lo que ya no se intuye bajo las zarzas, el esplendor y la riqueza que en aquellos lugares habitaron. Monumentos que pretenden mostrar lo que no se puede ver (Wajcman, 2001).

Para lograr en la investigación una simetría entre monumento escultórico y "monumento" botánico tomamos como caso paradigmático las palmeras indianas que se encuentran en $L a$ Quinta De Guadalupe. Ubicada en Colombres, concejo de Ribadedeva (Asturias), villa indiana por excelencia en la que abundan las casas y palmeras indianas. Esta casa, actual Museo de la Emigración de Asturias y Archivo Indiano, pertenecía al indiano Íñigo Noriega de Laso. A su actual valor institucional, muy en consonancia con la investigación que nos ocupa y que ha sido uno de los archivos consultados, se añade el valor simbólico que suma la biografía del que fuera su propietario Íñigo Noriega. Este indiano fue responsable y artífice de la desecación del Lago Chalco, ecocidio que en su momento fue considerado uno de sus logros empresariales. El lago se encuentra en Xico, un municipio de las afueras de la capital mexicana, y es uno de los lagos sobre los que se asentaba el imperio azteca. íñigo Noriega usurpó y explotó estos recursos naturales que pertenecían a las comunidades locales. La desecación del lago supuso el colapso del comercio de la región al destruir las chinampas (islas artificiales) de diseño indígena que producían millones de toneladas de maíz, siendo la base de la alimentación de miles de personas. (Somovilla, 2015). Este desastre actualmente sigue teniendo consecuencias ecológicas, paisajísticas y sociales. Inundaciones, agua contaminada, derrumbamientos, etc...su "hazaña ha sido materia para una investigación desde la práctica artística realizada por María Thereza Alves (2012). 
En un mundo completamente transformado por el ser humano todas las especies actuales son extrañas allí donde se encuentran (Thompson, 2019). El picudo rojo es un insecto del sudeste asiático, coleóptero considerado especie invasora, el cual ha padecido la desaparición de su entorno y también de sus depredadores, a causa de la deforestación de los bosques de los que es autóctono. De color rojo y tamaño de un dedo, su llegada a España a partir de 1993, en pleno boom inmobiliario, como ya expliqué anteriormente, fue debida a la alta demanda de palmeras para la urbanización de las zonas del Levante ${ }^{13}$. Su consecuente escasez hizo que fuera necesario importarlas y así llegaron los ejemplares infectados con picudo ${ }^{14}$ que ya entonces era considerado plaga a nivel europeo e internacional. En los 70 había puesto en riesgo la producción de cocos en el mundo y era, y sigue siendo, un problema en la producción de dátiles en Marruecos y Arabia Saudí. Su llegada a Gondomar es una amenaza que sugiere el preludio de la desaparición de las palmeras indianas ilustrando las consecuencias del capitalismo extractivo. Una rueda que no se detiene y genera nuevos paisajes como este mismo. Coincidiendo en el tiempo su llegada a Vigo con el traslado y sustitución del monumento de Colón en Buenos Aires, la observación de estos monumentos vivos infectados y el desplazamiento del monumento a Colón por una memoria descolonizada, nos ofrecen la lectura de un paisaje en el que se inscriben y recogen los problemas y memoria de nuestro tiempo.

Cabe añadir para profundizar en esta reflexión que estas palmeras, (salvando las excepciones de villas indianas como Colombres o Ribadeo) por su condición de plantas extranjeras no gozan de protección ni interés a pesar de ser centenarias y en muchos casos poder ser catalogadas como árboles singulares, lo cual ha supuesto que muchas hayan sido erradicadas. En Galicia recogí dos testimonios que así me lo confesaron, en ambos casos para ser sustituidas por árboles autóctonos (estás fueron las palabras textuales a las que se añadieron comentarios que daban cuenta de una conciencia medioambiental con marcada ideología). El picudo como la palmera no son autóctonos, ello los ubica en un lugar en el que solo la industria de las invasiones foráneas ve potencial en ellos. El valor de ser nativo guarda relación con la ilustración y los principios de la colonialidad. La autoctonía en botánica se establece como uno de los grandes principios, casualmente en el mismo s. XIX. Si bien desde la Edad Media existían los herbarios y desde el XVI el estudio en jardines botánicos de las plantas para la medicina es a raíz de la conquista que la idea de un mundo sin descubrir lleno de paisajes vírgenes, llenos de plantas desconocidas, recala en un imaginario que después, en la época de los viajes y el inicio de la comercialización de plantas dará lugar a la construcción de jardines. Se desarrollará entonces un saber botánico que cataloga y clasifica para aprender de la naturaleza desde la razón. Ahí se forja esta idea de paisaje prístino, una mirada de conquista y dominación que se establece en supuestos de un mundo detenido hasta nuestra llegada. Las plantas se clasifican y ordenan como se tomaba posesión de la naturaleza y del territorio, renombrando hasta lo que ya tenía nombre. La colonialidad dio por lo tanto forma a nuestro conocimiento ilustrado y clasificó el mundo vegetal por su origen, a pesar de que plantas y animales siempre han sido especies en movimiento, antes incluso de que nuestra intervención los haya acelerado (Mancuso, 2019). Ya entonces se observaron los desplazamientos de especies que se estudiaban y se problematizó la concepción originaria, a pesar de lo cual nuestra concepción ecológica aun hoy está marcada por esta cuestión. La idea del control humano que tenemos sobre las especies y nuestro interés en diseminar discriminadamente nos inclina a pensar que limitarse a lo autóctono entraña un mayor compromiso con el ecosistema. Una construcción distorsionada del mundo, profundamente 
ideológica, como si fuera este un escenario primigenio en el que especies que no son foráneas, son plaga, invasoras, un síntoma de contagio (Thompson, 2019). Que pensemos aun hoy desde esta concepción se añade y recoge en esta investigación, ya que simbólicamente es revelador de las implicaciones coloniales en el problema medioambiental, que afecta al objeto de estudio y revela nuevos significados. No es casual que el concepto de invasor este asociado directamente a la idea de plaga, de perjudicial y malo, sin embargo, nuestra influencia en la dispersión de las especies o el incremento de la temperatura nos hace directamente responsables de la mayor parte de los problemas que generan estos desplazamientos de fauna y flora. Nuestro sistema genera este impacto y aunque comienza a haber una preocupación por el cuidado del entorno, bien podrían ser estas imágenes un espejo que nos devuelve la complejidad de un mundo en constante cambio y ahora además sumamente alterado por nosotros.

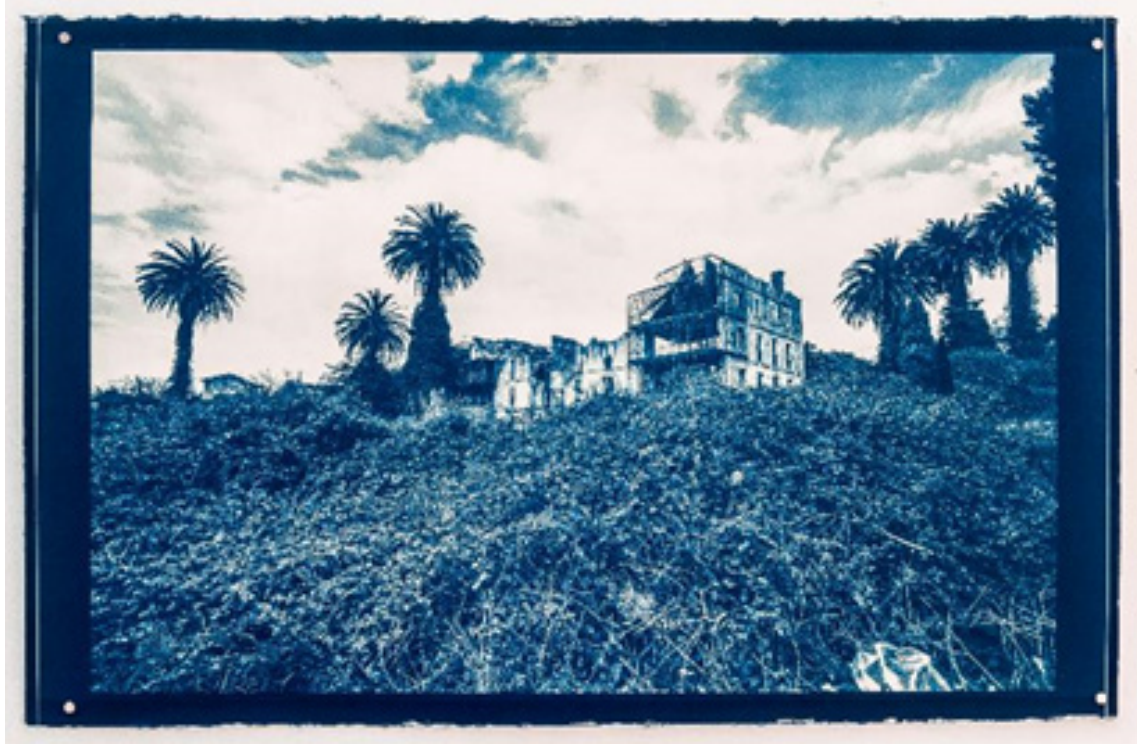

Figura 3. "Monumentos vivos y plagas biológicas, Pendueles" de la serie Cartografías para historia de nuestro tiempo proyecto ROJOULTRAMAR. Fuente: https://www.rakelgomezvazquez.com

3 Rojoultramar, materia para una investigación desde la práctica

Esta investigación que vengo presentando sigue un proceso de conceptualización a partir de lecturas, bibliografía, estudio de los contextos históricos e investigaciones afines basadas en prácticas artísticas. Como el caso de la investigación El retorno del lago, realizado la artista brasileña María Thereza Alves para la Documenta de Kassel. Proyecto que conocí en mi primera visita al Archivo de Indianos que traza relaciones y rastrea el alcance de la dominación colonial en la naturaleza. Como hasta ahora se ha podido leer, la observación de las circunstancias y la realidad del coleóptero, así como las vicisitudes y contexto de los monumentos, conforman un campo de trabajo, un material que permite una conceptualización y una proyección plástica que he llamado Rojoultramar. Mapas, esquemas, documentos, rutas y estudios botánicos significan el complejo diseño de un relato no lineal de la historia desde el que esbozar una 
relectura de esta amenaza. El archivo visual acumulado se convierte en material para una investigación desde la cianotipia, técnica de fotografía analógica que se vincula al proyecto en dos direcciones: históricamente, al tratarse de una técnica decimonónica, época del movimiento migratorio indiano, y simbólicamente, a través de su intenso color azul ultramar, a los procesos migratorios y comerciales. A su pertinencia en la construcción de sentido se suma además la toma de referencia de la botánica Ana Atkins (considerada primera fotógrafa de la historia) con su libro "British algae: cyanotype impressions" (considerado el primer fotobook), algas británicas impresas con cianotipias, un libro de saber científico. Su relación entre arte y ciencia es un referente en la observación para un conocimiento científico.

El arte, como método investigador, permite yuxtaponer disciplinas como la botánica, la historia o la biología y momentos históricos diferentes, para ponerlos en relación. Una forma de reflexión que tiene una naturaleza relacional (Elo, 2019) fruto de un conocimiento intuitivo. Analizando y estudiando desde el arte el impacto de insectos sobre un sujeto simbólico vivo, y observando en paralelo la remoción del monumento a Colón para analizar los efectos de ida y vuelta de la política colonial, podemos no solo visualizar sino reflexionar y especular a través de una metodología que no solo es discursiva, sino relacional y deíctica. El arte como práctica deíctica nos sitúa como observadores del mundo, señalamos, llamamos la atención determinando significados entre acontecimientos. Una práctica que no esta orientada a buscar soluciones y que deja patente mi posición investigadora como observadora del mundo.

El rasgo distintivo de una explicación deíctica no es su método, sino su sujeto, algo único
y concreto que está en el centro de atención y de su mundo. El discurso deíctico no tiene
que ver con garantizar o demostrar una verdad - lo cual no puede ni pretende hacer-,
sino con señalar lo que importa, lo que vale la pena. Tiene que ver, básicamente, con
plantear la pregunta acerca de su valor. En el discurso deíctico o la práctica deíctica,
la fuerza del argumento está en el testimonio; la o el artista habla fundamentalmente
como testigo. (Wesseling, 2019, p.160)

Algunas partes de la investigación desde la práctica artística no se ajustan a dimensiones orales o escritas y por lo tanto dificultan su contextualización en un conocimiento académico ilustrado. Según Borgmann (como se citó en Wesseling, 2019) las explicaciones deícticas señalan algo en su significado. La obra (Anábasis) tiene esa llegada para quien la contempla dado que el arte encierra la posibilidad de comunicar lo incomunicable, es un señalador. Sabemos que, a falta de garantías de códigos comunes, algunas partes del proceso investigador en arte pertenecen a la sombra de la producción (Catábasis) ${ }^{15}$. Y que es precisamente la problemática de lograr un método que nos permita comunicar lo incomunicable el origen de obra y el impulso para desarrollar una práctica investigadora (Gómez Vázquez, 2018). Investigar desde la práctica artística puede ser una oportunidad de reinterpretar la historia y generar una nueva lectura sobre los ejercicios de decolonización ya que nuestra propia metodología está problematizada desde la construcción colonial quedando fuera de la investigación el cuerpo, es decir, lo sensorial y lo sentido; la subjetividad; la ficción y la imaginación. La legitimación de nuestras investigaciones choca por lo tanto con el concepto establecido de la construcción de conocimiento y saber, y la concepción del arte y sus posibilidades metodológicas. Cómo legitimamos un saber situado que es producido, planteado y desarrollado por el mismo sujeto es una de las primeras cuestiones a las que la investigación desde la práctica se debe enfrentar (Haraway,1995). Los protocolos académicos establecen pautas y procesos que están directamente enfrentados a una práctica investigadora desde el arte. La genialidad del artista, por supuesto hombre, heterosexual y 
blanco, que crea por inspiración y a partir de sí mismo se establece desde que la modernidad deja de vincular el arte con lo sagrado y al artista con el chamán, el vidente.

"Una de las grandes fuerzas de la imagen es crear al mismo tiempo síntoma (interrupción en el saber) y conocimiento (interrupción en el caos)" (Didi-Huberman, 2013, p.26). Más allá de la videncia como concepto esotérico, el artista como el poeta percibe y siente. Nombra un malestar, un síntoma, desde un análisis sensible. Es decir, la centralidad del sujeto en la observación es clave. Que no haya distancia entre quien observa y el objeto de estudio está radicalmente enfrentado con los preceptos de entender la naturaleza desde la razón. Cuando el artista señala como un vidente y comunica lo que ve, porque lo siente, media entre un síntoma y el observador al que quiere comunicar algo o con quien quiere entrar en comunicación.

\subsection{Sintomático}

Tomando en cuenta que las palmeras son atacadas por una plaga invasora, pero ellas mismas son extranjeras, que simbólicamente se las juzga como objeto que legitima un discurso colonial y que el mantenimiento y prevención de la infección supone un gran desembolso económico, no es descabellado pensar que estos ejemplares en su mayoría desaparecerán en los próximos años. El monumento palmera queda afectado por su propio relato, la conquista y el poder. A consecuencia de aquello que simboliza ha llegado hasta aquí, ella y un insecto que provoca su muerte por infección. Mientras en el mismo tiempo Colón es desplazado y sustituido por simbolizar el genocidio y etnocidio de los pueblos americanos y su cosmovisión. Las palmeras indianas, árboles centenarios y memoria viva, están encarnando el mito de la política colonial extractiva. Puede ser esto comprendido como un síntoma que se manifiesta.

Una especie arbórea centenaria, traída para simbolizar un éxito, está prácticamente condenada a desaparecer. No es casual, es un síntoma de nuestro tiempo colonial. La percepción de algo que está sucediendo nos es refrendado por un conocimiento sensible. Hacemos una construcción de sentido, el malestar nos invita a que busquemos el síntoma. La pregunta se construye desde un análisis sensible, desde una práctica investigadora. Escritura y observación revierten formalmente y viceversa, no ilustran unas ni textualizan otras, el corpus que se construye simultáneamente avanza y se modifica formalmente porque la propia investigación lo demanda.

Resulta disruptivo reconocer simbólicamente la desaparición de un ser vivo vegetal, probablemente por la misma razón que no se contempló históricamente la alteridad, la otredad. Cuando comencé a cartografiar estos seres vivos que pronto ya no estarán, generé un material documental que tenía un carácter solemne, digno y muy vertical (ver Fig. 3). Tomando en cuenta esto, las fotografías de estos monumentos vivos pueden adquirir un sentido nuevo en una nueva disposición. El proceso del avance de la plaga tiene una correspondencia formal: desde la verticalidad se pasa a la desaparición, al suelo. 


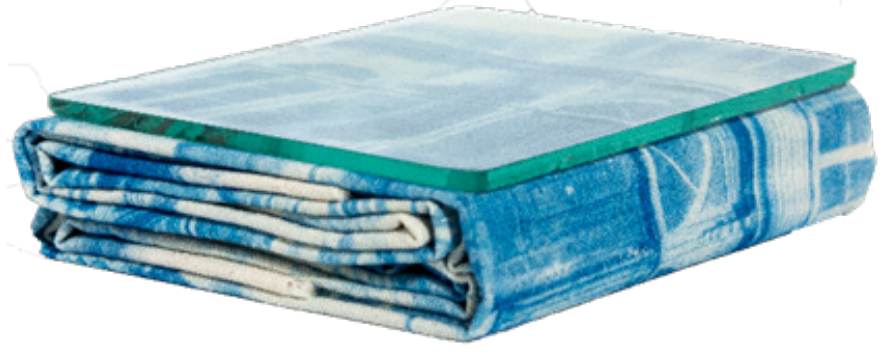

Figura 4. "Sintomático (Detalle). Fuente: https://www.rakelgomezvazquez.com

Las imágenes cartográficas de estas palmeras, ahora impresas en lienzo, toman una nueva disposición al ser dobladas y plegadas. Sintomático es una pieza que recurre a los plegados de banderas, a los honores de los cortejos fúnebres, buscando en un ritual reconocido y en la repetición del objeto visibilizar la dimensión del impacto que padece actualmente este elemento simbólico. La pieza tiene un procedimiento performativo (el de doblado y disposición de cada una de las imágenes plegadas en el suelo para evocar y subrayar esos rituales fúnebres). Cuando finalmente las piezas están dispuestas todas en un espacio, se ve como formalmente han cambiado. Ahora estas imágenes ya no permiten observar el paisaje que retratan, son un volumen (ver Fig. 4), su disposición es en el suelo perdiendo la verticalidad, porque de esta manera obligan a una nueva relación del cuerpo con ellas. Procurando una toma de conciencia de lo sintomático en cómo nos ubicamos ante las piezas, los cambios operan en la posición del espectador. En esta pieza se procura recuperar el relato simbólico frente al hecho, descentralizar el impacto de los datos científicos y potenciar la subjetivación. Escuchemos al síntoma pues nos permite construir la pregunta (Sztulwark, 2019). A partir de este daño, de esta señal, podemos ver qué no está funcionando.

\section{CONCLUSIONES}

[...] tampoco los muertos estarán seguros ante el enemigo cuando éste venza. Y este enemigo no ha cesado de vencer. [...] Quien hasta el día actual se haya llevado la victoria, marcha en el cortejo triunfal en el que los dominadores de hoy pasan sobre los que también hoy yacen en tierra. Como suele ser costumbre, en el cortejo triunfal llevan consigo el botín. Se le designa como bienes de cultura. [...] Jamás se da un documento de cultura sin que sea a la vez barbarie. E igual que él mismo no está libre de barbarie, tampoco lo está el proceso de transmisión en el que pasa de uno a otro. (Benjamin, 1973, pp.175-191).

Investigando la influencia colonial en la construcción visual y simbólica y analizando su proyección en el paisaje, observo cómo mientras un cambio de paradigma recupera otras memorias que posibilitan nuevos relatos opacados, en paralelo, la naturaleza opera y los ecos y consecuencias de una política colonial migratoria y extractiva nos permiten hacer una relectura crítica del patrimonio cultural y de las consecuencias del capitalismo. Desarrollando una práctica documental expandida, retratando el símbolo colonial que subyace en las palmeras indianas de La Quinta Guadalupe, he buscado la conexión entre indianos y picudo rojo como migraciones 
forzosas en tiempos históricos distintos.

Habitualmente ante el concepto de especies invasoras nos ubicamos agraviados, inocentes y que poco o nada tenemos que ver con su llegada. Hemos acelerado esta dispersión, pero el lenguaje nos delata en nuestro talante reprobatorio, la misma manera de referirnos a ellas como invasoras denota nuestra hipocresía. La idea de paisajes prístinos sigue indeleble en nuestro imaginario explorador de nuevos mundos. Existe una idea de alteración del medio que permite proteger a nuestras especies, a las que consideramos como tal. Juzgamos a las alóctonas como el dominado al colonizado, un síndrome de invasor que extrapolamos cuando rompen un equilibrio que nos afecta. Algunas nuevas corrientes paisajistas hace mucho que ponen en cuestión estas corrientes conservacionistas que hablan de: natural de, plantas y especies originarias de. Es sabido y demostrado que las plantas siempre viajaron y la naturaleza es un equilibrio de adaptación al contexto bien lejos del paraíso romántico o imaginario del Edén (Clément, 2017). Nuestra distorsión del mundo, de marcada ideología colonial, es una causa directa de nuestra incomprensión del reino vegetal como lo habrá sido de otras alteridades. Nuestra escala temporal nos incapacita para comprehender el tiempo y la dimensión de la vida en la escala tiempo de las plantas (Mancuso, 2019). Las repercusiones que podría tener contemplar estas cuestiones tal vez nos permitirían un cambio de paradigma, una memoria decolonizada en una mayor dimensión. Aspirar a una otredad aún más extensa. Comprender la palmera indiana como un símbolo de la evolución de nuestro esquema cultural, una planta que es un ser vivo y habita y padece unas circunstancias. Leer en ella un entorno que hemos transformado completamente y por lo cual vino hasta aquí y la hemos enfermado. Una representación e imagen cargada de nuevos significados. Porque, aunque siguen funcionando simbólicamente, podemos intuir que el poder ya no está en el palacio, el palacio indiano también está siendo devorado, lo vemos también en sus palmeras, y en el nuevo significado de los hoy ecocidios y antes "hazañas". Ahora podemos ver aquí mismo el daño, la plaga opera en el monumento vivo hasta matarlo, su desaparición, paradoja, es el síntoma.

Una nueva situación política en Latinoamérica pone el arte al servicio de una política decolonial. Cuando la figura de Colón es sustituida por Juana Azurduy cabría preguntar qué valores antagónicos, no sobre la figura de Colón, sino sobre la colonialialidad, se inscriben en esta nueva figura. Si bien trata de desmontar la presentación eurocéntrica, sexista y patriarcal, ¿hasta dónde se estaría estableciendo un cambio de paradigma que nos situé en una nueva lectura? La imagen pareciera que se construye en asimetría a la otra y por lo tanto guarda correspondencia. Se crea con toda la intención manifiesta de que sea un monumento. ¿No es ello una marca inconsciente de la herencia decimonónica? Si bien el ser humano toma posesión de un espacio y lo convierte en su territorio mediante operaciones retóricas, la propia idea de monumento, de imagen que rememora con una intención manifiesta pedagógica ¿no vuelve a repetir la misma dialéctica con el espectador? ¿No es esto volver a tomar el territorio con soberanía? ¿No sería por lo tanto un nuevo ejercicio colonial? Es decir, la correspondencia que guarda, aunque sea contraria (mujer-hombre, Fé-Razón, civilización-barbarie), el carácter hipernarrativo que quiere ser simbólico (tanto en la antigua como en la nueva figura) donde nada es dejado a la construcción del espectador, ¿no vuelve a operar por todo ello con un lenguaje soberano y certero? ¿No lo distancia esto del arte? ¿Se corresponde de alguna manera la nueva figura con un imaginario de los pueblos originarios? ¿Sería posible después de todo volver a representar desde otra cosmovisión que es ajena al artista y al territorio en el que va a ser emplazado?

Son necesarias imágenes que autoafirmen y queden fuera del imaginario civilizatorio y liberal, 
así lo demandan las comunidades originarias, pero ¿estaríamos con esta nueva figura diseñando otra forma para hacer memoria y política sobre el territorio que dé respuesta a esa necesidad? El arte como revelador de nuevos significados y alteridades aun no reconocidas es herramienta para ofrecer mensajes que no sean cerrados. Puede hacer que nos preguntemos o incluso que respondamos subjetivamente. ¿No sería esta una práctica emancipadora más en sintonía con una práctica decolonial? Formular un mensaje que no es cerrado, que deja nuevas preguntas para un mundo atravesado hoy por una pandemia con repercusiones aún desconocidas en la gestión de movimientos migratorios, globalidad y colonialidad.

\section{REFERENCIAS}

Alves, M. T. (2012). The return of a lake. El retorno de un lago. Universidad Autónoma de México, México D.F. Recuperado de: www.caac.es/programa/alves14/frame.html

Benjamin, W. (1973). Discursos interrumpidos I. Madrid, España: Taurus.

Bores Gamundi, F. (2000) (coord.). Casas de indianos. Xunta de Galicia: Secretaría Xeral para as Relacións coas Comunidades Galegas.

Clément, G. (2017). El jardín en movimiento. Barcelona, España: Gustavo Gili.

Calero, C. (16.07. 2015). Kirchner, Evo, Colón y la heroína del Alto Perú. El mundo. Recuperado de https://www.elmundo.es/americ a/2015/07/16/55a7004446163f56178b45ab.html

Elo, M. (2019). Paradojas de la investigación artística. En Rita Sixto y Usoa Fullaondo (Eds.), Piscina. Investigación y practica artística. Maneras y ejercicios (pp.179-194). Bilbao, España:

Ediciones laSia.

Figueroa, E.M. y Rojo, M.T (2009). La Palmera, Símbolo de Poderío o Contribución al Sistema Verde en un Escenario de Cambio Climático. Taller Capital y territorio. ¿La construcción de un sueño? Universidad Internacional de Andalucía. Recuperado de http://ayp.unia.es/dmdocuments/com18.pdf

Freedberg, D. (2017). Iconoclasia: Historia y psicología de la violencia contra las imágenes. Vitoria- Gasteiz, España: Sans Soleil.

Gamboni, D. (2014). La destrucción del arte: Iconoclasia y vandalismo desde la Revolución Francesa. Barcelona, España:

Cátedra. 
Gómez Vázquez, R. (2018). A la sombra de la producción: aproximaciones y puesta en valor de la catábasis, extensión oculta del proceso creativo. AUSART, 6(1), 261-272. DOI: 10.1387/ausart.19464

Haraway, D.J. (1995). Ciencia, cyborgs y mujeres. La invención de la naturaleza. Madrid, España: Cátedra.

Didi-Huberman, G. (2013). Cuando las imágenes tocan lo real. Madrid, España: Ediciones Círculo de Bellas Artes.

Latour, B. (2002). Iconoclash, Beyond the Image-Wars in Science, Religion and Art. Recuperado de https://www.sfu.ca/cmns/ courses/2011/488/1Readings/IconoclashLatour\%20lconoclash. pdf

Le Goff, J. (1989). Documento/Monumento. IRARGI, Revista de Archivística, 2, 103-131.

Morales Saro, M.C y Llordén Miñambres, M. (1992). Arte, cultura y sociedad en la emigración española a América. Universidad de Oviedo, Oviedo: Servicio de Publicaciones.

Martínez Ron, A. (19.05.2016). Una carrera para salvar las palmeras indianas. Vozpopuli. Recuperado de https://www. vozpopuli.com/altavoz/next/Biologia-SeleccionNext-Especies_ invasoras-Picudos-Palmeras-Plagas-Galicia_0_918208208.html

Mancuso, S. y Vittola, A. (2015). Sensibilidad e inteligencia en el mundo vegetal. Madrid, España: Galaxia Gutenberg.

Mancuso, S. (2019). El increíble viaje de las plantas. Madrid, España: Galaxia Gutenberg.

Ortemberg, P. (2016) Monumentos, memorialización y espacio público: reflexiones a propósito de la escultura de Juana Azurduy. Tarea, 3(3), 96-125.

Padin, L. (2015). El vuelco latinoamericano: de Cristóbal Colón a Juana Azurduy. Buenos Aires, Argentina: Ediciones de la UNLA.

Pérez, F. (09.11.2008). La plaga que trajo la burbuja del ladrillo. El País. Recuperado de https://elpais.com/diario/2008/11/09/ andalucia/1226186526_850215.html

Pigna, F. (02.06.2020). Juana Azurduy, amazona de la libertad, ElHistoriador.com, s.d. Recuperado de https://www.elhistoriador. com.ar/juana-azurduy-amazona-de-la-libertad/ 
Riegl, A. (1987). El culto moderno a los monumentos. Madrid, España: Visor.

Santos González, Y. (2020). Morriña de Cuba. A Coruña a través de sus palmeras. Asociación Morriña de Cuba.

Somovilla, I. (2015). El sueño del indiano: jardín privado, jardín público. En F. Moral Pérez (Presidencia) Conferencia inaugural Ilevada a cabo en el XLII Congreso de la Asociación Española de Parques y Jardines Públicos, Oviedo. Recuperado de https:// ignaciosomovilla.files.wordpress.com/2015/04/el-suec3b1o-delindiano-amb-fotos.pdf

Sztulwark, D. (2019). La ofensiva sensible. Buenos Aires, Argentina: Caja Negra.

Thompson, K. (2016). ¿De dónde son los camellos? Creencias y verdades sobre las especies invasoras. Madrid, España: Alianza editorial.

Yaccar, D. (15.07. 2015). Pienso en Juana como una interpelación. Página12. Recuperado de https://www.pagina12.com.ar/diario/ suplementos/espectaculos/6-36072-2015-07-15.html

Wesseling, J. (2019). Investigación artística en la Academy of Creative and Performing Arts, Universidad de Leiden. En Rita Sixto y Usoa Fullaondo (Ed.), Piscina. Investigación y practica artística. Maneras y ejercicios (pp.179-194). Bilbao, España: Ediciones laSia.

Wajcman G. (2001). El objeto del siglo. Buenos Aires, Argentina: Amorrortu. 
1. Si bien la infección aún no ha llegado a Colombres se espera de manera inminente con gran preocupación, pues ya hay casos en la provincia de Asturias.

Ver: https://www.elcomercio.es/asturias/plaga-picudo-rojo-palmeras-asturias20180223010818-ntvo.html?ref=https:\%2F\%2Fwww.google.com

2. www.archivodeindianos.es/portada_intro.html

3. "Informe técnico sobre el monumento a Cristóbal Colón y la plaza homónima", Buenos Aires 3 de junio de 2013. Cfr. Recuperado de: http://bastadedemoler.org/?p=6392

4. Esta guerra de esculturas fue un síntoma de la batalla cultural librada durante el Bicentenario de Mayo entre el Gobierno de la Ciudad de carácter opositor y el Gobierno Nacional. Mientras que el arco opositor exaltaba a la Argentina del Centenario para legitimar su balance negativo de la Argentina del Bicentenario, el oficialismo hacía exactamente lo inverso y se concretaba en el reemplazo de la estatua de Colón, metonimia de un "Centenario europeísta, masculino y de la oligarquía", por la escultura de Juana Azurduy, en tanto metonimia de un "Bicentenario latinoamericanista, femenino y popular" (Ortemberg, 2016).

5. "Yo tengo documento italiano", dice Zerneri. "Y no tengo problema en correr ese monumento. Porque Colón no es el que me enseñaron cuando era chico. Hoy pensamos otra cosa. Ya no estamos agradeciéndole tener cultura, lengua o ropa. Nos remite a muchas desgracias que tienen que ver con la imposición de una cultura por sobre otra. No hubiera estado de acuerdo con destruir ese monumento, como se hizo en casi todos los países de Latinoamérica; sí con que se lo restaure y se lo lleve a otro lugar. Colón, como buen caballero, le ha cedido el asiento a esta señora de la Patria Grande. Y él va a estar bien. Va a seguir mirando al río, a Europa" (Yaccar, 2015).

6. "Lo más probable es que ella haya sido diestra con la espada. Pero quise sacarle el rigor bélico. Que sea sostenida con una mano en términos más liberadores. Como si la espada se transformase en una bandera, una antorcha. No porta la espada con la mano que mata, sino con la que libera" (Yaccar, 2015).

7. Aunque para lograr una simetría entre monumento escultórico y "monumento" botánico en la investigación singularizamos las palmeras de la Quinta Guadalupe (Archivo de Indianos y Museo de la Emigración de Asturias) comenzamos un análisis generalista de las palmeras indianas.

8. El papel simbólico le corresponde por lo general a la palmera: el mítico arbor victoriae tan identificativo del mundo indiano y emblema distintivo de esta condición de su propietario. En lo que fue una costumbre casi universal en este periodo, los espacios delanteros de la arquitectura indiana situados entre la carretera y la vivienda venían presididos las más de las veces por ella, a modo de obeliscos vegetales frente a los pilonos de unos nuevos templos indianos. Este papel simbólico hace que, aunque pueda plantarse como elemento aislado integrada con otros árboles, o como árbol de alineación definiendo una avenida, la costumbre general sea plantarlas por parejas frente al acceso principal y bien visibles 
desde el camino exterior (Bores Gamundi, 2000).

9. Aquellos, los menos, que lograron volver con fortuna benefactores de los lugares que les vieron nacer, plantaron sus palmeras en la entrada de sus casonas o palacetes de estilo colonial, significando que allí vivía uno que "lo había logrado", que había logrado "hacer las Américas". Ej. La Ruta de los Indianos en el Municipio de Ribadedeva (Asturias) (Figueroa y Rojo, 2009).

10. El mero concepto de "arquitectura indiana" ya es de por si mismo muy sugerente, y no exento de polémica ya que viene dado por el único requisito de haber sido costeado con dinero procedente de América, sin que encuentre este origen ningún cauce estilístico uniforme, sino todo lo contrario, produciéndose un amplio repertorio artístico. Los ejemplos los encontraremos en toda Asturias, con desigual densidad según los concejos. No fue tampoco un fenómeno exclusivo de Asturias, sino que se reprodujo con similares parámetros en Castilla, Cantabria, Galicia, Canarias, Cataluña... Somovilla, I. (2015). El sueño del indiano: jardín privado, jardín público. En F. Moral Pérez (Presidencia) Conferencia inaugural llevada a cabo en el XLII Congreso de la Asociación Española de Parques y Jardines Públicos, Oviedo. Recuperado de: https://ignaciosomovilla.files.wordpress.com/2015/04/ el-suec3b1o-del-indiano-amb-fotos.pdf

11. "conquistadores" de paraísos terrenales. También la palmera, como ya se ha mencionado, es un símbolo que porta el carácter de emblema de los conquistadores de paraísos, en la cultura occidental, quizás desde los viajes de Colón y luego rememorada por los viajes de los "Indianos", o emigrantes o descendiente de emigrantes españoles (jóvenes, de Galicia, Canarias, Asturias, Cantabria, el País Vasco y Cataluña) que a lo largo del siglo XIX y principios del XX, emigraron a las antiguas colonias españolas de América (Cuba, Argentina, Uruguay, Venezuela o México) motivado por el afán de hacer fortuna (Figueroa y Rojo, 2009).

12. Esa posición preeminente las ha hecho muy vulnerables a la ampliación de los caminos. Así, si alguna vez fueron arrancadas porque sus fuertes raíces agrietaban los edificios, la mayoría de las desapariciones se deben a la ampliación de las carreteras a las que con tanta frecuencia se adosaban estas edificaciones, como se evidencia una y otra vez en el Inventario, del que entresacamos, entre otros muchos, el ejemplo de La Perla del Sur (Bores Gamundi, 2000).

13. No hay depredadores naturales porque los bosques de donde viene ya han desaparecido. En España está claro que entró en Motril en los años 90 como consecuencia del 'boom' urbanístico: los especuladores importaron palmeras datileras que venían del norte de África cuando se acabaron las de los viveros y en sus hojas venía el picudo". Y las consecuencias de aquella época de corrupción y esplendor amenazan ahora a las palmeras que vinieron de América con los emigrantes gallegos. Martínez Ron, 2016).

14. "No es una invasión natural de un insecto, sino una invasión de palmeras infestadas, importadas y distribuidas por toda la costa con el visto bueno de los servicios de sanidad vegetal", denuncia el científico francés Michel Ferry, director de investigación de la Estación Phoenix, un organismo creado por el Ayuntamiento de Elche para el estudio de la palmera datilera. Otra leyenda urbana descartada: el picudo tampoco es consecuencia 
del cambio climático. "Eso lo han dicho los políticos en alguna ocasión para sacudirse la responsabilidad" (Pérez, 2008).

15. La investigación artística engloba la obra final (Anábasis) y la sombra de la producción (Catábasis). (...) Catábais, la parte oculta, la parte oscura, lo que no se muestra y lo que está a la sombra de la producción, aquellos tránsitos procesuales, que incluyen también los fracasos. (...) se baja a lo profundo (cátabasis) para volver a subir y comunicar lo descubierto (Anábasis). (Gómez Vázquez, 2018). 